\title{
EFFECT OF PRODUCTION PARAMETERS ON THE ECONOMIC FEASIBILITY OF A BIOFUEL ENTERPRISE
}

\author{
SAMUEL D. ZAPATA* \\ Department of Agricultural Economics, Texas AঊM AgriLife Extension Service, Texas AঊM University, Weslaco, \\ Texas \\ LUIS A. RIBERA \\ Department of Agricultural Economics, Texas A\&M AgriLife Extension Service, Texas A\&M University, College \\ Station, Texas \\ MARCO A. PALMA \\ Department of Agricultural Economics, Texas AઐM AgriLife Extension Service, Texas AઐM University, College \\ Station, Texas
}

\begin{abstract}
In order to guarantee the success of the nascent cellulose-based biofuel industry, it is crucial to identify the most economically relevant components of the biofuel production path. To this aim, an original stochastic financial model is developed to estimate the impact that different feedstock production and biofuel conversion parameters have on the probability of economic success. Estimation of the model was carried out using Monte Carlo simulation techniques along with parametric maximum likelihood estimation procedures. Results indicate that operational efficiency strategies should concentrate on improving feedstock yields and extending the feedstock growing season.
\end{abstract}

Keywords. Binary response model, cellulose-based biofuel, energy cane, marginal effects, Monte Carlo simulation, net present value

JEL Classifications. Q16, C15, Q14, G17

\section{Introduction}

The latest Renewable Fuel Standard (RFS2) mandate is both a challenge and an opportunity for the biofuel industry. Namely, the RFS2 specifies a target of 36 billion gallons for total renewable transportation fuels by 2022, of which 16 billion gallons have to be cellulosic biofuels. Additionally, cellulosic biofuels are required to reduce greenhouse gas emissions by at least $60 \%$ compared with the petroleum fuels they would replace.

In order to fulfill these new environmental and production regulation goals, there is a need for the optimal allocation of resources. Particularly, substantial

*Corresponding author's e-mail: samuel.zapata@ag.tamu.edu 
research is needed to assess and improve the probability of economic success of current and future biofuel investments while reaching the program goals. To this aim, it is crucial to better understand the effects that production factors have on the economic feasibility of a biofuel enterprise to effectively target future improvement efforts. Special attention has to be given to developing more efficient production systems to generate cellulose-based biofuels because they represent approximately $45 \%$ of the RFS 2 mandate.

Even though some efforts have been made to evaluate the effect of both feedstock and biofuel production parameters on the feasibility of a biofuel enterprise, little work has been conducted to identify and assess the impact of production parameters on the probability of economic success. Previous studies have focused on traditional sensitivity analysis, which consists of evaluating the economic feasibility of a project under a reduced and discrete set of possible production scenarios (e.g., Marvin et al., 2012; Ribera et al., 2007; Swanson et al., 2010; Wright et al., 2011). Few of the preceding sensitivity analyses have included a broader range of production parameters and possible values, and little attention has been given to assess the effect that individual changes on the production parameters have on the probability of economic success.

The main objective of this study is to extend the current literature regarding economic feasibility of cellulosic biofuel production. Specifically, we evaluate the impact that the different feedstock production and biofuel conversion parameters have on the probability of economic success, where economic success is defined in terms of the net worth of the project. An original stochastic financial model is developed to analyze and identify the most economically relevant components of the biofuel production path. Current and projected energy prices along with industry and research production parameters are used to generate potential production scenarios. Simulated data are used to evaluate the individual effects of production parameter changes on the probability of economic success. This study provides insights to improve production systems by better targeting future research efforts.

\section{Background and Literature Review}

Currently, the most promising biofuel feedstock are dedicated energy grasses because of their high biomass yield, high fiber content, broad genetic diversity, and demonstrated capability to thrive on marginal lands not ideal for food, feed, or fiber production (McCutchen, Avant, and Baltensperger, 2008; van der Weijde et al., 2013). In terms of feedstock conversion technologies, different options are available including hydrolysis, gasification, pyrolysis, and acetone-butanolethanol. Hydrolysis is the most economically feasible conversion process in the current state of the economy because of having lower operating and capital expenses, less dependence on government incentives, and higher changes of 
economic success by improving feedstock and biofuel conversion yields (Monge et al., 2014).

Different metrics have been developed and used to assess the economic feasibility of planned investments. In terms of renewable energy projects, suggested analytical valuation tools include the following: net present value (NPV), benefit-cost ratio, internal rate of return, least cost planning, payback period, and sensitivity analysis (Owens, 2002). Other authors have suggested the use of more complex but flexible valuation approaches such as real option analysis (Cai and Stiegert, 2014; Gonzalez, Karali, and Wetzstein, 2012; Pederson and Zou, 2009; Schmit, Luo, and Tauer, 2009). All the aforementioned valuation tools are interrelated, and each of them explores specific features of the project cash flow. For example, the NPV uses the time value of money to convert a stream of annual cash flow generated through the life span of a project to a single value for a given discount rate (Owens, 2002). Projects with positive NPVs are considered profitable or an economic success ${ }^{1}$ (Remer and Nieto, 1995).

Normally, the technical and financial components of the project are expressed in an NPV pro forma. This pro forma is defined at an initial valuation stage, and then it is used in the estimation of further economic feasibility metrics (e.g., Monge et al., 2014; Richardson et al., 2007). Consequently, understanding the specific sources of variation of the NPV is of vital importance because those project parameters causing positive impacts on the NPV might also lead to improvements on other feasibility metrics of interest.

The economic feasibility of using new dedicated energy crops or crop residues as feedstock sources has been extensively studied (e.g., Bansal et al., 2013; Epplin et al., 2007; Haque and Epplin, 2012; Khanna, Dhungana, and Clifton-Brown, 2008; Marvin et al., 2012; Miranowski and Rosburg, 2010; Swanson et al., 2010; Tao et al., 2014; Wright et al., 2010). Other studies have evaluated the economic feasibility of sugarcane as a potential feedstock for sugar-based ethanol (e.g., Coyle, 2010; Outlaw et al., 2007; Ribera et al., 2007; Shapouri, Salassi, and Fairbanks, 2006). However, little work has been conducted to identify and assess the impact of both feedstock and biofuel production parameters on the probability of economic success. The traditional approach to evaluate the effect of production parameters on the economic feasibility is to evaluate the NPV of a new project under a reduced and discrete set of possible production scenarios. Namely, each scenario considered includes only a limited number of production parameters, and the parameters of interest are set to discrete and predetermined values (e.g., Joelsson et al., 2016; Wu, Sperow, and Wang, 2010). Recent studies have introduced more flexibility to the sensitivity analysis by defining some parameters in each considered scenario as stochastic variables, such as feedstock

1 Besides profitability, there are other intrinsic economic components of a project that are not considered in the NPV such as the opportunity cost of time and money. In practice, other valuation metrics and analyses are used as complements to NPV. 
yields and biofuel prices, and then calculating the probability of success (i.e., positive NPV) under the fixed parameters settings (e.g., Linton et al., 2011; Monge et al., 2014; Palma et al., 2011; Ribera et al., 2007; Richardson, Lemmer, and Outlaw, 2007).

This study extends the current economic feasibility literature by developing a flexible stochastic financial model able to analyze and identify the most economically relevant components of the biofuel production path. To the best of our knowledge, this is the first study that quantifies the effect of each production parameter on the probability of observing a positive NPV. Additionally, the applications of the proposed approach can be extended to the valuation of other projects beyond renewable energy investments.

\section{Methods}

The NPV is one of the standard metrics to assess the economic feasibility of a new project. The NPV is defined as the sum of all net cash flows of a project over a period of time discounted to an equivalent present date (Remer and Nieto, 1995). In our particular case, the NPV is a function of several feedstock and biofuel production parameters such as expected feedstock yield, energy prices, biofuel conversion rate, and feedstock and biofuel production costs. Given a specific set of $m$ inputs $(\boldsymbol{X})$, the NPV is given by the deterministic function

$$
N P V=f(\boldsymbol{X}) \text {. }
$$

In general, a project is accepted if its NPV is positive and rejected if the NPV is negative. If the NPV is equal to zero, then the investor is indifferent in the decision whether to accept or reject the project (Remer and Nieto, 1995). Through the article, a positive NPV is considered economic success, and a nonpositive NPV is seen as economic failure.

\subsection{Financial Model}

The feedstock and biofuel production models and financial pro forma developed and described in Monge et al. (2014) are used in this article. Namely, the hydrolysis conversion technology and its corresponding production path are used to assess the effect of feedstock and biofuel production parameters on the probability of obtaining a positive NPV. Although the proposed analysis can be extended to any biofuel production process, we focused on ethanol produced from energy cane through a hydrolysis conversion process.

Particularly, the ethanol production path is divided into two production stages: feedstock production and biofuel production. At the first stage, energy cane is planted and harvested for a period of 5 years. On an annual basis, the number of harvesting months (HarvMonth) depends on seasonal and agronomic limitations. The overall cost to deliver energy cane as feedstock to a conversion plant comprises the energy cane production cost (FeedPrdCost), return to producers 
(Return) expressed as percentage over the production cost, variable harvesting and hauling cost (VarHrvCost) depending on the energy cane yield (Yield_EC), and fixed harvesting and hauling cost (FxHrvCost).

In the subsequent production stage, the energy cane feedstock supplied to the conversion plant is transformed into ethanol through a hydrolysis conversion process. It is assumed that the total feedstock demand is fully met without shortage. Moreover, the total annual feedstock demand is a function of the conversion plant's nameplate capacity (FuelPrd) and biofuel conversion yield (FuelYld). It is further assumed that total investment in the conversion plant, plant operating expenses, and fixed expenses are functions of the plant's nameplate capacity. Additionally, excess electricity is generated as a by-product of transforming energy cane into ethanol. Plant revenues come from selling the produced ethanol and excess electricity at expected energy prices (Price_Ene). The NPV is estimated over a 10 -year planning horizon using an $8 \%$ discount rate. For specific details about the ethanol production path considered in this study and its corresponding financial statements, see Monge et al. (2014).

Compared with the original model in Monge et al. (2014), where most of the feedstock and biofuel production parameters were fixed at current industry estimates, we define the different production parameters of interest as random variables and allow them to take values within a continuous, reasonable range of possible alternatives following a uniform distribution.

\subsection{Data Generation}

Monte Carlo simulation techniques were used to generate $n\left\{N P V_{i}, \boldsymbol{X}_{i}\right\}$ samples, where the subscript $i$ denotes the $i$ th iteration. The vector $X$ represents all the exogenous and independent parameters of the NPV function. The true underlying probability distribution function of most production parameters is unknown; thus, a uniform distribution function (Unif) was assigned to each parameter. Consequently, on each iteration the value of $X$ can be represented as a random deviation relative to the baseline scenario $\mathcal{X}$. Namely, $\boldsymbol{X}_{i}$ can be defined as

$$
\boldsymbol{X}_{i}=\left(\mathbf{1}_{m}+\boldsymbol{\delta}_{i}\right) \circ \mathcal{X}
$$

where the operator $\circ$ denotes the Hadamard or entrywise product, $\mathbf{1}_{m}$ is an $m$ vector of ones, and $\boldsymbol{\delta}_{i}$ is an $m$ vector with its elements $\left(\delta_{i j}\right)$ independent and uniformly distributed from $\omega_{j}-$ to $\omega_{j}+$. Therefore, the $\delta_{i j}$ 's can be seen as percentage deviations from the baseline scenario. In other words, the NPV generated on each iteration is a nonstochastic realization of a particular set of production parameters (i.e., $\boldsymbol{X}$ ), where the vector $\boldsymbol{X}$ randomly changes for each iteration. Thus, variations on the probability of economic success are not assessed on each iteration but on the whole simulated data set. A total of 10,000 iterations were simulated to analyze the effect of production parameters on the NPV. Each iteration may be a unique combination of production parameter values, and 
Table 1. Baseline Scenario and Distribution Range

\begin{tabular}{|c|c|c|c|c|}
\hline Parameter & Acronym & Units & Baseline & Distribution Function \\
\hline Harvest months & HarvMonth & month & 9.5 & Unif $(8.00,11.00)$ \\
\hline Production cost & FeedPrdCost & $\$ / a c$. & 450 & Unif $(350.00,550.00)$ \\
\hline Return to producers & Return & $\%$ & 20 & Unif $(10.00,30.00)$ \\
\hline Energy cane yield & Yield_EC & dst/ac. & 20 & Unif $(17.50,22.50)$ \\
\hline $\begin{array}{c}\text { Variable harvesting } \\
\text { and hauling cost }\end{array}$ & VarHrvCost & $\$ /$ dst & 10 & Unif $(7.50,12.50)$ \\
\hline $\begin{array}{l}\text { Fixed harvesting and } \\
\text { hauling cost }\end{array}$ & FxHrvCost & $\$ / a c$. & 92 & Unif $(69.00,115.00)$ \\
\hline $\begin{array}{c}\text { Ethanol annual } \\
\text { production }\end{array}$ & FuelPrd & million gal. & 30 & Unif $(25.00,35.00)$ \\
\hline Biofuel yield & FuelYld & gal./dst & 85 & Unif $(75.00,95.00)$ \\
\hline Energy prices & Price_Ene & $\begin{array}{l}\text { \$/gal. } \\
\$ / \mathrm{kWh}\end{array}$ & $\begin{array}{l}2013 \text { EIA } \\
\text { reference case }\end{array}$ & EIA* Unif $^{*}(0.75,1.25)$ \\
\hline
\end{tabular}

Note: dst, dry short ton; EIA, U.S. Energy Information Administration.

consequently, every generated iteration can be considered as a realization of a possible production scenario.

The baseline scenario and the considered range of each parameter are described in Table 1. The baseline scenario represents the latest industry and research production parameters in south Texas. The parameter values are based on a discussion panel of local sugarcane producers and energy cane yields and production cost obtained from large experimental field plots in Weslaco, Texas, managed by Texas A\&M AgriLife Research and Extension Center. On the baseline scenario, energy cane is harvested for 9.5 months, and the production cost is equal to $\$ 450$ per acre. Also, the producers' return for growing energy cane is set to $20 \%$ of the preharvest or standing production cost. The 2014 average energy cane yield of 20 dry short tons (dst) per acre is used as the baseline feedstock yield. The variable and fixed costs to harvest and deliver the produced feedstock to the conversion plant are equal to $\$ 10 / \mathrm{dst}$ and $\$ 92 / \mathrm{ac}$., respectively. The conversion plant's nameplate capacity is 30 million gallons of ethanol a year, and 1 dst of energy cane yields 85 gallons of ethanol. Because of the lower current energy prices, the 2013 U.S. Energy Information Administration (EIA) Reference Scenario for ethanol and electricity was used for the 10-year planning horizon of the project (EIA, 2013). Namely, the forecasted and nominal before tax ethanol wholesale prices and electricity prices for the generation sector were used. The purpose of using the 2013 energy prices was to represent a more likely future situation.

Under the uniform distribution function, each possible outcome within a bounded interval has the same probability of occurrence. Interval boundary values were set to be equal to the interval limits considered in the original study or 

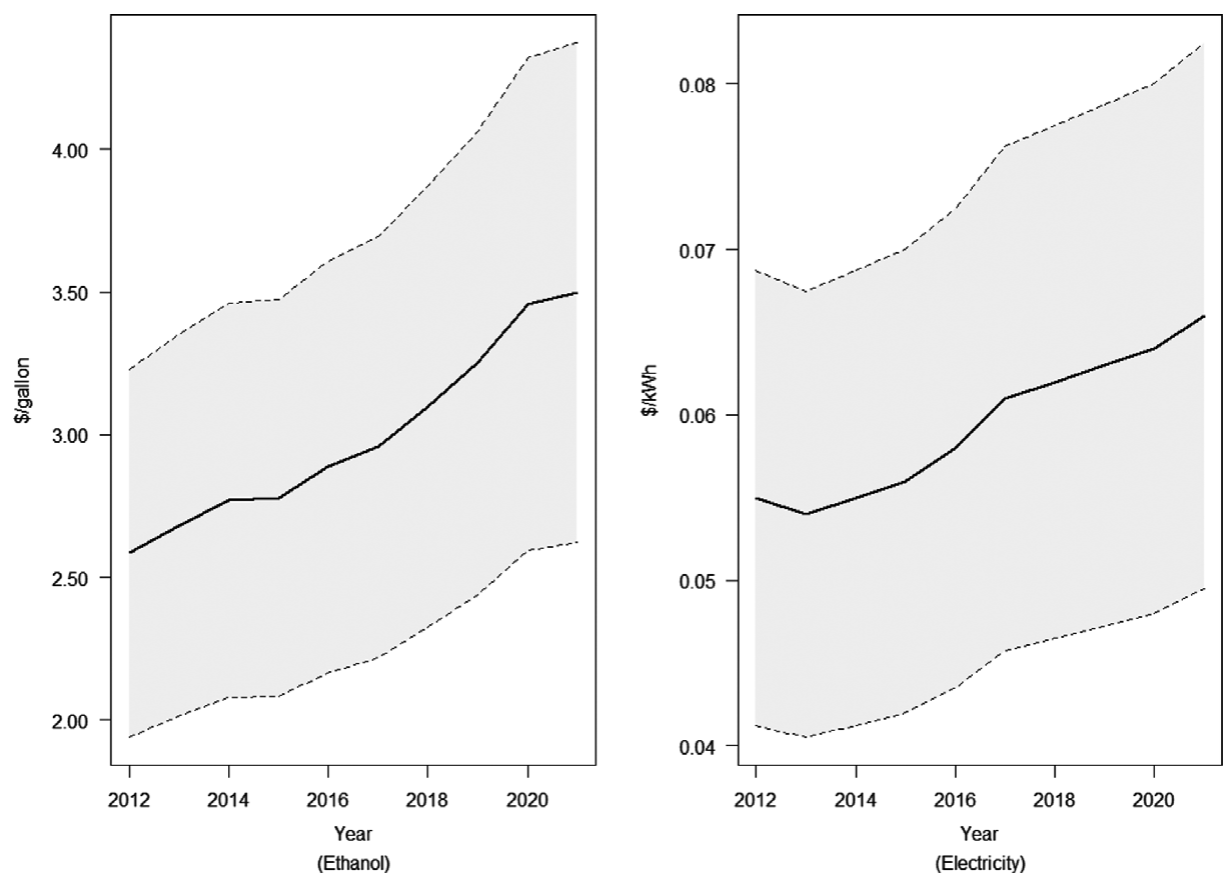

Figure 1. 2013 Ethanol and Electricity U.S. Energy Information Administration Reference Price Scenario (dotted lines represent $\pm 25 \%$ from the baseline price trend)

current industry observable values. In the case of ethanol and electricity prices, it is expected that these two parameters are intrinsically related to each other, tending to move in the same direction. In order to avoid multicollinearity issues, their corresponding projected 10-year price trends shift proportionally to the random energy price deviation parameter $\left(\delta_{\text {Price_Ene }}\right)$. For example, if $\delta_{\text {iPrice_Ene }}$ is equal to $5 \%$, then the yearly ethanol and electricity prices used to estimate the NVP in the $i$ th iteration are both $5 \%$ higher than the EIA Reference Scenario. The 2013 EIA Reference Scenario for both ethanol and electricity prices is shown in Figure 1.

\subsection{Conceptual Framework}

The complex deterministic function $f(\cdot)$ in equation (1) can be approximated by a functional form $h(\cdot)$. Thus, the NPV is expressed as a conditional function of $\boldsymbol{\delta}_{i}$ given $\mathcal{X}$ plus an error term. Specifically,

$$
\begin{aligned}
N P V_{i} & =h\left[\left(\mathbf{1}_{m}+\boldsymbol{\delta}_{i}\right) \circ \mathcal{X}\right]+\varepsilon_{i} \\
& =b\left(\boldsymbol{\delta}_{i} \mid \mathcal{X}\right)+\varepsilon_{i}, \quad i=1,2, \ldots, n,
\end{aligned}
$$


where the $\varepsilon_{i}$ 's are assumed to be independent and identically distributed errors, with zero mean, finite variance, and cumulative density function (CDF) $F_{\varepsilon}$.

The probability of economic success can be estimated by specifying the NPV in equation (1) as an ordinal variable. Namely, the generated NPVs are transformed to a binary variable $(Y)$ such that

$$
Y=\left\{\begin{array}{ll}
1 & \text { if } N P V>0 \\
0 & \text { if } N P V \leq 0
\end{array} .\right.
$$

Then, by equation ( 3 ) the probability of observing a positive NPV (i.e., $Y_{i}=1$ ) given a set of production parameters can be written as follows:

$$
\begin{aligned}
\operatorname{Pr}\left(Y_{i}=1 \mid \boldsymbol{\delta}_{i}, \mathcal{X}\right) & =\pi_{i}=\operatorname{Pr}\left(N P V_{i}>0\right) \\
& =\operatorname{Pr}\left[h\left(\boldsymbol{\delta}_{i} \mid \mathcal{X}\right)+\varepsilon_{i}>0\right] \\
& =\operatorname{Pr}\left[\varepsilon_{i}>-b\left(\boldsymbol{\delta}_{i} \mid \mathcal{X}\right)\right] \\
& =1-F_{\varepsilon}\left[-b\left(\boldsymbol{\delta}_{i} \mid \mathcal{X}\right)\right] .
\end{aligned}
$$

The probability function described in equation (5) can be further used to analyze the impact that changes on feedstock and biofuel production parameters have on the probability of economic success. In a practical sense, the marginal effects are defined as the changes on the probability of economic success by increasing the production parameters by $1 \%$ relative to the baseline scenario. Particularly, the marginal effect of the $j$ th parameter is given by the partial derivative

$$
\begin{aligned}
\frac{\partial \pi_{i}}{\partial \delta_{i j}} & =\frac{\partial F_{\varepsilon}}{\partial h} \frac{\partial h}{\partial \delta_{i j}} \\
& =\frac{\partial b}{\partial \delta_{i j}} f_{\varepsilon},
\end{aligned}
$$

where $f_{\varepsilon}$ is the marginal density of $\varepsilon$. Therefore, the marginal effects can be used to identify the most economically relevant production parameters and to quantify their impact on the probability of economic success. Improvement efforts can then be primarily focused on those parameters with the largest marginal effects.

\subsection{Model Estimation}

Maximum likelihood techniques were used to estimate the aforementioned model. Specifically, given $n$ observations, the generic likelihood function associated with the probabilities in equation (5) can be defined as

$$
L=\prod_{i=1}^{n} \pi_{i}^{y_{i}}\left(1-\pi_{i}\right)^{1-y_{i}}
$$


With the aim to keep the results easier to interpret, it was further assumed that $h(\cdot)$ in equation (3) is given by a linear function of the form

$$
\begin{aligned}
h\left(\boldsymbol{\delta}_{i} \mid \mathcal{X}\right) & =\beta_{0}+\sum_{j=1}^{m} \beta_{j}\left[\left(1+\delta_{i j}\right) \mathcal{X}_{j}\right] \\
& =\alpha_{0}+\sum_{j=1}^{m} \alpha_{j} \delta_{i j},
\end{aligned}
$$

where $\beta$ s are function parameters, and $\alpha_{0}=\beta_{0}+\sum_{j=1}^{m} \beta_{j} \mathcal{X}_{j}$ and $\alpha_{j}=\beta_{j} \mathcal{X}_{j}$. Note that the functional form in equation (8) is expressed as a function of the percentage deviations from the baseline scenario.

Two distribution functions were considered to model the distribution of $\varepsilon$. Specifically, the standard normal and logistic distributions were used to analyze the effect of production parameters on the probability of economic success. These two distributions are commonly used in the literature to model binary data (e.g., Hoetker, 2007; Long, 1997).

Under the normal distribution, the probability of observing a positive NPV is given by

$$
\pi_{i}=\Phi\left(\alpha_{0}+\sum_{j=1}^{m} \alpha_{j} \delta_{i j}\right)
$$

where $\Phi(\cdot)$ is the CDF of the standard normal distribution function. Furthermore, it can be shown that the marginal effect of the $j$ th production parameter is given by

$$
\frac{\partial \pi_{i}}{\partial \delta_{i j}}=\alpha_{j} \phi\left(\alpha_{0}+\sum_{j=1}^{m} \alpha_{j} \delta_{i j}\right)
$$

where $\phi(\cdot)$ is the marginal density function of the standard normal distribution.

The probability of observing a positive NPV when the errors are assumed to follow a logistic distribution is equal to

$$
\pi_{i}=\frac{e^{\left(\alpha_{0}+\sum_{j=1}^{m} \alpha_{j} \delta_{i j}\right)}}{1+e^{\left(\alpha_{0}+\sum_{j=1}^{m} \alpha_{j} \delta_{i j}\right)}} .
$$

Similarly, it can be shown that the marginal effect of the $j$ th production parameter is given by

$$
\frac{\partial \pi_{i}}{\partial \delta_{i j}}=\alpha_{j} \pi_{i}\left(1-\pi_{i}\right) .
$$


The marginal effects presented in this study were calculated as the average marginal effects across the $n$ iterations. Marginal effects' standard errors were estimated using the delta method (Greene, 2012).

Given the nonnested nature of the models considered in this study, the distribution that "best fitted" the data was selected using the Akaike information criterion (AIC) (Akaike, 1974). The AIC is a log-likelihood-based model selection criterion adjusted by the number of independent parameters. Given a data set and several candidate models, the model with the smallest AIC is preferred

\section{Results}

The estimated total cost to produce a gallon of ethanol from energy cane under the baseline scenario assumptions is $\$ 2.13$ without any government incentives. This cost includes $\$ 0.49 / \mathrm{gal}$. for the cost of feedstock, $\$ 0.87 / \mathrm{gal}$. to convert the feedstock into ethanol, $\$ 0.50 /$ gal. in interest expenses, $\$ 0.37 /$ gal. in dividends, and an additional revenue of $\$ 0.09 / \mathrm{gal}$. because of selling of excess electricity. Even though this cost structure is consistent with other cellulosic feedstocks (Bansal et al., 2013; Epplin et al., 2007; Haque and Epplin, 2012; Khanna, Dhungana, and Clifton-Brown, 2008; Tao et al., 2014), lower production costs have been reported in both the United States and Brazil using sugar-based feedstock alternatives (Coyle, 2010; Outlaw et al., 2007; Ribera et al., 2007; Richardson et al., 2007; Shapouri, Salassi, and Fairbanks, 2006).

The overall mean for the simulated NPVs was $-\$ 31.38$ million with a standard error of $\$ 0.73$ million. The maximum and minimum observed NPVs were $\$ 189.24$ million and $-\$ 222.17$ million, respectively. Also, based on the Monte Carlo simulations, 3,487 iterations were considered as economic successes (i.e., NPV $>0$ ), and 6,513 iterations were defined as economic failures (i.e., NPV $\leq 0$ ). The 10,000 generated NPVs are shown in Figure 2.

Normal and logistic distributions were used to model the probability of obtaining a positive NPV given a set of production parameters. Model estimation results for both the normal and logistic distributions along with the corresponding AIC are presented in Tables 2 and 3, respectively. The AIC suggests that the preferred distribution is the normal distribution. Therefore, the normal distribution results are further used to discuss the impact of feedstock production and biofuel conversion parameters on the probability of economic success. It is important to note that the marginal effect estimates were robust across the two candidate models considered in this study. Thus, from a practical perspective and for this particular application only, there is no significant difference between using either the logistic or normal model.

The normal distribution marginal effects of the different production parameters are presented in Table 2. These marginal effect estimates are interpreted as the percentage increase in the probability of observing a 
Table 2. Normal Distribution Coefficient and Marginal Effect Estimates

\begin{tabular}{|c|c|c|c|c|}
\hline Parameter & Coefficient & Standard Error & Marginal Effect & Standard Error \\
\hline Constant & $-9.580^{\mathrm{a} * * *}$ & 0.545 & & \\
\hline Harvest months & $0.895^{* * *}$ & 0.051 & $1.321^{* * *}$ & 0.149 \\
\hline Production cost & $-0.133^{* * *}$ & 0.009 & $-0.196^{* * *}$ & 0.023 \\
\hline Return to producers & $-0.024^{* * *}$ & 0.002 & $-0.036^{* * *}$ & 0.005 \\
\hline Energy cane yield & $1.032^{* * *}$ & 0.058 & $1.523^{* * *}$ & 0.172 \\
\hline $\begin{array}{c}\text { Variable harvesting } \\
\text { and hauling cost }\end{array}$ & $-0.048^{* * *}$ & 0.005 & $-0.071^{* * *}$ & 0.010 \\
\hline $\begin{array}{l}\text { Fixed harvesting and } \\
\text { hauling cost }\end{array}$ & $-0.024^{* * *}$ & 0.005 & $-0.036^{* * *}$ & 0.008 \\
\hline $\begin{array}{c}\text { Ethanol annual } \\
\text { production }\end{array}$ & $0.260^{* * *}$ & 0.016 & $0.384^{* * *}$ & 0.044 \\
\hline Biofuel yield & $0.214^{* * *}$ & 0.015 & $0.316^{* * *}$ & 0.038 \\
\hline Energy prices & $1.260^{* * *}$ & 0.071 & $1.860^{* * *}$ & 0.210 \\
\hline $\begin{array}{l}\text { Akaike information } \\
\text { criterion }\end{array}$ & 556.828 & & & \\
\hline
\end{tabular}

a Significance levels of $0.01,0.05$, and 0.10 are indicated by ${ }^{* * *},{ }^{* *}$, and ${ }^{*}$, respectively.

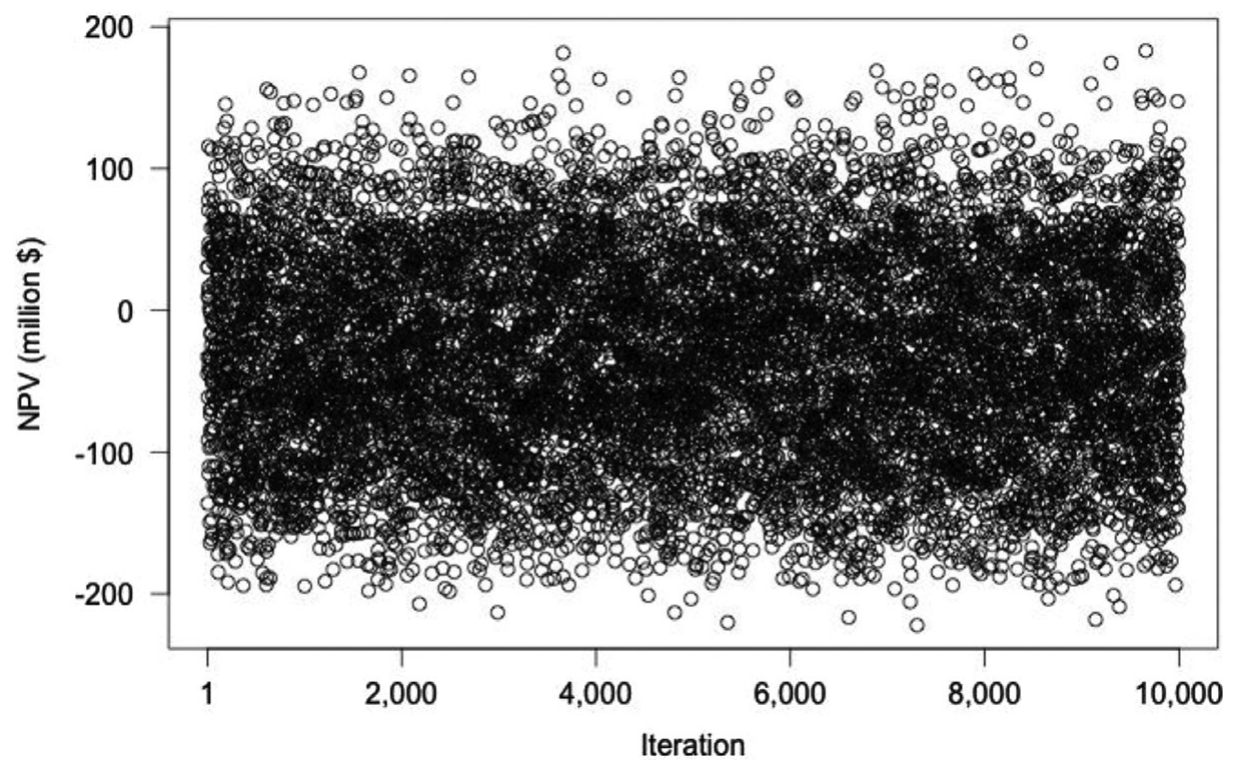

Figure 2. Monte Carlo Simulated Net Present Values (NPVs)

positive NPV by increasing the production parameters by $1 \%$ relative to the baseline scenario. It is relevant to mention that the likelihood of changing the production parameters is not the same across all parameters. Some production parameters could be improved by achievable industry technological 
Table 3. Logistic Distribution Coefficient and Marginal Effect Estimates

\begin{tabular}{lcccc}
\hline \hline Parameter & Coefficient & Standard Error & Marginal Effect & Standard Error \\
\hline Constant & $-17.153^{\text {a***}}$ & 1.044 & & \\
Harvest months & $1.604^{* * *}$ & 0.098 & $1.316^{* * *}$ & 0.012 \\
Production cost & $-0.239^{* * *}$ & 0.017 & $-0.196^{* * *}$ & 0.007 \\
Return to producers & $-0.044^{* * *}$ & 0.005 & $-0.036^{* * *}$ & 0.003 \\
Energy cane yield & $1.850^{* * *}$ & 0.112 & $1.518^{* * *}$ & 0.013 \\
$\quad \begin{array}{l}\text { Variable harvesting } \\
\quad-0.086^{* * *}\end{array}$ & 0.009 & $-0.071^{* * *}$ & 0.006 \\
$\quad$ and hauling cost & $-0.044^{* * *}$ & 0.008 & $-0.036^{* * *}$ & 0.006 \\
$\quad$ Fixed harvesting and & & & $0.383^{* * *}$ & 0.008 \\
$\quad$ hauling cost & $0.467^{* * *}$ & 0.030 & $0.319^{* * *}$ & 0.013 \\
$\quad$ pthanol annual & & & $1.855^{* * *}$ & 0.014 \\
Biofuel yield & $0.389^{* * *}$ & 0.028 & & \\
Energy prices & $2.26^{* * *}$ & 0.137 & & \\
Akaike information & 561.522 & & & \\
$\quad$ criterion & & & & \\
\hline \hline
\end{tabular}

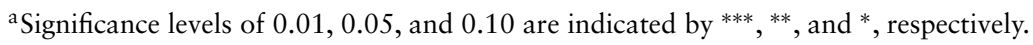

advancements, whereas others are driven by exogenous and variable economic and political circumstances.

Simulation results based on south Texas production conditions suggest that the probability of economic success increases by $1.32 \%$ if the parameter of energy cane harvesting months is extended by $1 \%$ (or 2.85 days). Prolonging the harvest window of dedicated energy crops has been identified as a key economic challenge to the new cellulose-based biofuel industry (Epplin et al., 2007). A suggested possibility to extend the harvest windows is to consider a variety of feedstocks including both cellulosic and sugar-based options (Monge et al., 2014).

The marginal effects also indicate that increasing the overall cost to produce and deliver the feedstock including energy cane production cost, producers' returns, and harvesting and hauling costs has a negative impact on the probability of obtaining a positive NPV. Namely, increasing the feedstock production cost by $1 \%$ (or by $\$ 4.5 / \mathrm{ac}$.) reduces the probability of observing a positive NPV by $0.20 \%$. Similarly, the probability of economic success is reduced by $0.04 \%$ when the return to producers increases by $1 \%$. In addition, unit percent increases on the variable and fixed harvesting and hauling costs reduced the probability of economic success by $0.07 \%$ and $0.04 \%$, respectively. Lower biomass production costs have been gauged to be essential to guarantee the success of next-generation biofuels mainly because lower feedstock production costs are needed to offset the higher conversion and capital costs associated with cellulosic biofuels relative to their counterpart sugar-based biofuels (Coyle, 2010). Feedstock production also needs to compete with other crops in terms of profits; thus, higher return rates 
may be needed to incentivize growers to switch from any incumbent crop to the new dedicated energy crops. Additionally, feedstock economic feasibility has been found to be sensitive to transportation and delivery costs (Linton et al., 2011). Government programs aimed to subsidize the different feedstock production costs may contribute to improve the possibility of economic success; however, the continuity of such programs is uncertain.

Based on the estimated marginal effects, improvements on energy cane yields will have a significant impact on obtaining a positive NPV. Specifically, simulation results indicate that a $1 \%$ increase on the feedstock yield (i.e., 0.2 dst/ac.) raises the probability of economic success by $1.52 \%$. In order to achieve the goals of the RFS2 mandate, this finding suggests that future research target efforts should increase biomass yields. Higher feedstock yields are expected to translate into lower costs of production of advanced biofuels. To this end, improving current feedstock yields will require a combination of multidisciplinary efforts to develop novel high-yielding varieties and optimal agronomic production practices especially under marginal land conditions.

In terms of ethanol conversion parameters, results indicate that both conversion plant's nameplate capacity and biofuel conversion yield are positively related to NPV. Namely, the probability of economic success increases by $0.38 \%$ and $0.32 \%$ with respect to unit percent increases in the total annual ethanol produced and ethanol conversion yield, respectively. The probability of economic success increases with plant production capacity because of economies of scale. As production scales up, the capital expenditure costs per unit of output decline. However, higher capital-investment costs are expected for cellulosic ethanol compared with sugar-based ethanol primarily because of higher feedstock preparation costs (Coyle, 2010; Shapouri, Salassi, and Fairbanks, 2006). Similarly, improvements on conversions rates are presumed to reduce the overall cost of ethanol production, but no data for commercial operations using energy cane exist to corroborate this fact. Higher plant construction costs along with higher uncertainty about untested conversion technologies on a large scale may reduce investors' willingness to support large cellulosic ethanol projects (Coyle, 2010). Currently, there are five cellulosic ethanol plants in the United States with production capacity between 6 and 30 million gallons per year, but only one of them is commercially producing ethanol (Renewable Fuels Association, 2016).

Lastly, energy prices play an important role in the probability of economic success. Particularly, a $1 \%$ positive shift of the ethanol and electricity price trends increases the probability of economic success by $1.86 \%$. Consequently, current lower energy prices may delay the development of future investment initiatives aimed to increase the production of cellulosic ethanol. In fact, it has been argued that substantially higher oil prices are needed to guarantee a steady market-based development and expansion of the cellulosic biofuel industry (Miranowski and Rosburg, 2010, 2013). 


\section{Summary and Conclusions}

The optimal allocation of resources and efforts is needed to fulfill the latest RFS2 mandate. Particularly, 16 billion gallons of cellulosic biofuels are envisioned to be produced by 2022. In order to guarantee the success of the nascent cellulose-based biofuel industry, it is crucial to better understand the effects that production parameters have on the economic feasibility of a biofuel enterprise to effectively target future improvement efforts. The main goal of this study was to estimate the impact that the different feedstock production and biofuel conversion parameters have on the probability of economic success.

A flexible stochastic financial model was developed in this article to analyze and identify the most economically relevant components of the biofuel production path. Although the proposed analysis can be extended to any biofuel production process, we focused on ethanol produced from energy cane through a hydrolysis conversion process. Estimation of the model was carried out using Monte Carlo simulation techniques along with parametric maximum likelihood estimation procedures.

This article provides insights to improve production systems by better targeting future research efforts. Simulation results indicate that the probability of economic success of transforming energy cane into ethanol can be increased by extending the feedstock harvest windows, reducing the overall feedstock production costs, including return to producers and harvesting and hauling costs, increasing feedstock yield, augmenting conversion plant's nameplate capacity, and improving biofuel conversion yield. Based on the magnitude of the marginal effects, the findings of this study suggest that operational efficiency strategies should concentrate on improving feedstock yields and extending the growing season. Energy prices were also found to have a significant impact on the probability of economic success; thus, higher energy prices may be needed to incentivize the development and expansion of the emerging cellulosic biofuel industry.

\section{References}

Akaike, H. "A New Look at the Statistical Model Identification." IEEE Transactions on Automatic Control 19,6(1974):716-23.

Bansal, A., P. Illukpitiya, S.P. Singh, and F. Tegegne. "Economic Competitiveness of Ethanol Production from Cellulosic Feedstock in Tennessee." Renewable Energy 59(November 2013):53-57.

Cai, X., and K.W. Stiegert. "Market Analysis of Ethanol Capacity." International Food and Agribusiness Management Review 17,1(2014):83-94.

Coyle, W.T. Next-Generation Biofuels: Near-Term Challenges and Implications for Agriculture. Washington, DC: U.S. Department of Agriculture, Economic Research Service, BIO-01-01, 2010.

Epplin, F., C. Clark, R. Roberts, and S. Hwang. "Challenges to the Development of a Dedicated Energy Crop.” American Journal of Agricultural Economics 89,5(2007):1296-302. 
Gonzalez, A.O., B. Karali, and M.E. Wetzstein. “A Public Policy Aid for Bioenergy Investment: Case Study of Failed Plants. Energy Policy 51(December 2012):465-73.

Greene, W.H. Econometric Analysis. 7th ed. Boston, MA: Pearson, 2012.

Haque, M., and F.M. Epplin. "Cost to Produce Switchgrass and Cost to Produce Ethanol from Switchgrass for Several Levels of Biorefinery Investment Cost and Biomass to Ethanol Conversion Rates." Biomass and Bioenergy 46(November 2012):517-30.

Hoetker, G. "The Use of Logit and Probit Models in Strategic Management Research: Critical Issues." Strategic Management Journal 28,4(2007):331-43.

Joelsson, E., B. Erdei, M. Galbe, and O. Wallberg. "Techno-economic Evaluation of Integrated First- and Second-Generation Ethanol Production from Grain and Straw.” Biotechnology for Biofuels 9(2016):1. doi:10.1186/s13068-015-0423-8.

Khanna, M., B. Dhungana, and J. Clifton-Brown. "Costs of Producing Miscanthus and Switchgrass for Bioenergy in Illinois.” Biomass and Bioenergy 32,6(2008): 482-93.

Linton, J.A., J.C. Miller, R.D. Little, D.R. Petrolia, and K.H. Coble. "Economic Feasibility of Producing Sweet Sorghum as an Ethanol Feedstock in the Southeastern United States." Biomass and Bioenergy 35,7(2011):3050-57.

Long, J.S. Regression Models for Categorical and Limited Dependent Variables. Advanced Quantitative Techniques in the Social Sciences, 7. Thousand Oaks, CA: Sage, 1997.

Marvin, W.A., L.D. Schmidt, S. Benjaafar, D.G. Tiffany, and P. Daoutidis. "Economic Optimization of a Lignocellulosic Biomass-to-Ethanol Supply Chain.” Chemical Engineering Science 67,1(2012):68-79.

McCutchen, B.F., R.V. Avant, Jr., and D. Baltensperger. "High-Tonnage Dedicated Energy Crops: The Potential of Sorghum and Energy Cane." Reshaping American Agriculture to Meet Its Biofuel and Biopolymer Roles: Proceedings of the Twentieth Annual Conference of the National Agricultural Biotechnology Council, Columbus, Obio, USA, 3-5 June 2008. Ithaca, NY: National Agricultural Biotechnology Council, 2008, pp. 119-122.

Miranowski, J., and A. Rosburg. "An Economic Breakeven Model of Cellulosic Feedstock Production and Ethanol Conversion with Implied Carbon Pricing." Department of Economics Working Paper, WP\#10002, Ames: Iowa State University, 2010.

—. "Long-Term Biofuel Projections under Different Oil Price Scenarios." AgBioForum 15,4(2013):79-87.

Monge, J.J., L.A. Ribera, J.L. Jifon, J.A. da Silva, and J.W. Richardson. "Economics and Uncertainty of Lignocellulosic Biofuel Production from Energy Cane and Sweet Sorghum in South Texas." Journal of Agricultural and Applied Economics 46,4(2014):457-85.

Outlaw, J.L., L.A. Ribera, J.W. Richardson, J. da Silva, H. Bryant, and S.L. Klose. "Economics of Sugar-Based Ethanol Production and Related Policy Issues." Journal of Agricultural and Applied Economics 39,2(2007):357-63.

Owens, G. Best Practices Guide: Economical and Financial Evaluation of Renewable Energy Projects. Washington, DC: U.S. Agency for International Development, 2002.

Palma, M.A., J.W. Richardson, B.E. Roberson, L.A. Ribera, J.L. Outlaw, and C. Munster. "Economic Feasibility of a Mobile Fast Pyrolysis System for Sustainable Bio-crude Oil Production." International Food and Agribusiness Management Review 14,3(2011):116.

Pederson, G., and T. Zou. "Using Real Options to Evaluate Ethanol Plant Expansion Decisions.” Agricultural Finance Review 69,1(2009):23-35. 
Remer, D.S., and A.P. Nieto. "A Compendium and Comparison of 25 Project Evaluation Techniques. Part 1: Net Present Value and Rate of Return Methods.” International Journal of Production Economics 42,1(1995):79-96.

Renewable Fuels Association. Fueling a High Octane Future: 2016 Ethanol Industry Outlook. Washington, DC: Renewable Fuels Association, 2016.

Ribera, L.A., J.L. Outlaw, J.W. Richardson, J. da Silva, and H. Bryant. "Integrating Ethanol Production into a U.S. Sugarcane Mill: A Risk Based Feasibility Analysis.” Agricultural and Food Policy Center (AFPC) Research Paper 07-1, College Station: AFPC, The Texas A\&M University System, 2007.

Richardson, J.W., B.K. Herbst, J.L. Outlaw, and R.C. Gill II. "Including Risk in Economic Feasibility Analyses: The Case of Ethanol Production in Texas." Journal of Agribusiness 25,2(2007):115-32.

Richardson, J.W., W.J. Lemmer, and J.L. Outlaw. "Bio-ethanol Production from Wheat in the Winter Rainfall Region of South Africa: A Quantitative Risk Analysis.” International Food and Agribusiness Management Review 10,2(2007):181-204.

Schmit, T.M., J. Luo, and L.W. Tauer. "Ethanol Plant Investment Using Net Present Value and Real Options Analyses." Biomass and Bioenergy 33,10(2009):1442-51.

Shapouri, H., M. Salassi, and J.N. Fairbanks. The Economics Feasibility of Ethanol Production from Sugar in the United States. Washington, DC: U.S. Department of Agriculture, 2006.

Swanson, R.M., J.A. Satrio, R.C. Brown, A. Platon, and D.D. Hsu. Techno-economic Analysis of Biofuels Production Based on Gasification. Golden, CO: National Renewable Energy Laboratory, 2010.

Tao, L., D. Schell, R. Davis, E. Tan, R. Elander, and A. Bratis. NREL 2012 Achievement of Ethanol Cost Targets: Biochemical Ethanol Fermentation via Dilute-Acid Pretreatment and Enzymatic Hydrolysis of Corn Stover. Golden, CO: National Renewable Energy Laboratory, 2014.

U.S. Energy Information Agency (EIA). Annual Energy Outlook 2013. Washington, DC: EIA, 2013.

van der Weijde, T., C.L.A. Kamei, A.F. Torres, W. Vermerris, O. Dolstra, R.G.F. Visser, and L.M. Trindale. "The Potential of C4 Grasses for Cellulosic Biofuel Production." Frontiers in Plant Science 4(May 2013):107. doi:10.3389/fpls.2013.00107.

Wright, M., J. Satrio, R. Brown, D. Daugaard, and D. Hsu. Techno-Economic Analysis of Biomass Fast Pyrolysis to Transportation Fuels. Golden, CO: National Renewable Energy Laboratory, 2010.

Wu, J., M. Sperow, and J. Wang. "Economic Feasibility of a Woody Biomass-Based Ethanol Plant in Central Appalachia." Journal of Agricultural and Resource Economics 35,3(2010):522-44. 